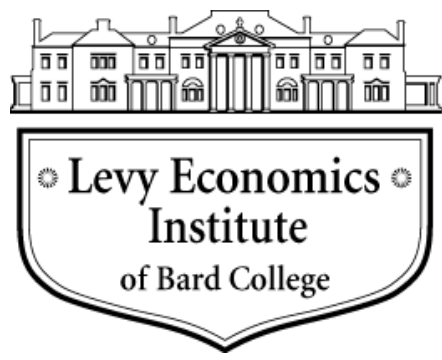

Working Paper No. 989

\title{
The Endogeneity-to-Demand of the National Emergency Utilization Rate
}

by

\author{
Michalis Nikiforos \\ Levy Institute \\ and \\ University of Geneva
}

June 2021

The Levy Economics Institute Working Paper Collection presents research in progress by Levy Institute scholars and conference participants. The purpose of the series is to disseminate ideas to and elicit comments from academics and professionals.

Levy Economics Institute of Bard College, founded in 1986, is a nonprofit, nonpartisan, independently funded research organization devoted to public service. Through scholarship and economic research it generates viable, effective public policy responses to important economic problems that profoundly affect the quality of life in the United States and abroad.

Levy Economics Institute

P.O. Box 5000

Annandale-on-Hudson, NY 12504-5000

http://www.levyinstitute.org

Copyright $($ Levy Economics Institute 2021 All rights reserved

ISSN 1547-366X 


\begin{abstract}
The paper provides an empirical discussion of the national emergency utilization rate (NEUR), which is based on a "national emergency" definition of potential output and is published by the US Census Bureau. Over the peak-to-peak period 1989-2019, the NEUR decreased by 14.2 percent. The paper examines the trajectory of potential determinants of capacity utilization over the same period as specified in the related theory, namely: capital intensity, relative prices of labor and capital, shift differentials, rhythmic variations in demand, industry concentration, and aggregate demand. It shows that most of them have moved in a direction that would lead to an increase in utilization. The main factor that can explain the decrease in the NEUR is aggregate demand, while the increase in industry concentration might have also played a small role.
\end{abstract}

KEYWORDS: Accumulation; Growth; Distribution; Utilization

JEL CLASSIFICATIONS: B22; O4; D3; D2 


\section{INTRODUCTION}

An important issue in macroeconomic theory is whether utilization is endogenous to demand or not. One way to approach this issue is through the analysis Duncan Foley and Tom Michl - and more recently in the second edition with Daniele Tavani - provide in their seminal book, Growth and Distribution (Foley and Michl 1999; Foley, Michl, and Tavani 2019). Moving from a "classical" model - where distribution is "conventional" (based on class struggle, institutions, and social norms) and the decision to invest and save is treated as the same- toward an "investment constrained" model where the decision to invest is separate from the decision to save implies the introduction of an extra equation (the investment function). Therefore, for the model not to be overdetermined necessitates the addition of one endogenous variable: the rate of capacity utilization.

Thus, an exogenous rate of utilization means that we either have to go back to the classical model, where aggregate demand does not play a role, or drop the assumption of conventional distribution and make distribution endogenous. The choice of the model has important consequences for the relation between wages and profits, the role of fiscal and monetary policy, Social Security, and technical change.

These are all issues Michl engaged with and made significant contributions to over the last nearly four decades, always keeping the role of demand and utilization explicit (Michl 1987, 2009, 2015; Michl and Foley 2004). He has always been inclined toward the classical model in the sense defined above (i.e., that the role of demand is limited and utilization is exogenous in the long run), but he has also always been pluralistic in his approach, genuinely interested in engaging and listening to other views and willing to change his own in the face of new evidence, such as the crisis of 2007-9 and the stagnant recovery that followed.

There are two sides in the debate on whether utilization is or is not endogenous to demand in the long run. The important questions on the theoretical side are: i) At the micro level, why would a firm adjust its normal utilization in the face of changes in demand? and ii) How are 
the changes at the micro level linked to the macroeconomy? While this discussion is beyond the scope of the present paper, the interested reader can refer to Nikiforos $(2013,2016$, $2020 \mathrm{~b}$ ) for a review of the literature and some justifications for why normal utilization is endogenous to demand.

On the empirical side the question is obviously about the related empirical evidence. The argument of those who support an exogenous-to-demand utilization is usually justified using the Federal Reserve Board's (FRB) measure of utilization, which fluctuates around the same center of gravity over long stretches of time.

There are two problems with this argument (Nikiforos 2016, 2021). First, if one looks at the way the FRB measure is constructed it is evident that it tends to be stationary by construction. Second, at a logical level, the theory of utilization posits a number of determinants of the normal rate of utilization (capital intensity, relative prices of labor and capital, shift differentials, rhythmic variations in demand, industry concentration). A constant utilization would mean that all these determinants move in such a way as to keep the overall rate constant. However, there is no convincing reason for this to happen.

Hence, we first need to go beyond the FRB rate. The important question is not if normal utilization is constant or not-it is not - but whether or not it is affected by demand. An alternative is the average workweek of capital (AWW), which measures how many hours per week an economy's capital stock is utilized. Estimates of the AWW point to a very different trajectory compared to the FRB series and seem to be affected by fluctuations in demand.

The present paper provides an empirical discussion of another measure of utilization, which is appropriate for measuring long-run variations of normal utilization: the national emergency utilization rate (NEUR), which is based on a "national emergency" definition of potential output and is published by the US Census Bureau. Over the peak-to-peak period 1989-2019 (which covers three cycles, two of them the longest in US history) the NEUR decreased by 14.2 percent. This paper examines the trajectory of capacity utilization's 
potential determinants of over the same period, demonstrating that most of them have moved in a direction that would have led to an increase in utilization. The main factor that explains the decrease in the NEUR is aggregate demand, while the increase in industry concentration might have also played a role.

\section{MEASURES OF CAPACITY UTILIZATION}

The empirical side of the capacity utilization debate is naturally based on various utilization measures. The most common of these measures is the one constructed for the United States economy by the FRB, presented in figure 1. As we can see, utilization fluctuates around the same level for long periods of time. For the period 1948-79 it fluctuated around 83.07 percent, while for the period 1979-2006 average utilization was 80.69 percent. ${ }^{1}$ Regressions for these two periods show that there is no trend in the data. The relative constancy of the FRB measure has been used as evidence to support the rate of utilization being exogenous to demand in the long run.

${ }^{1} 1948,1979$, and 2006 are all peak cycle years. 


\section{Figure 1: The FRB Measure of Capacity Utilization}

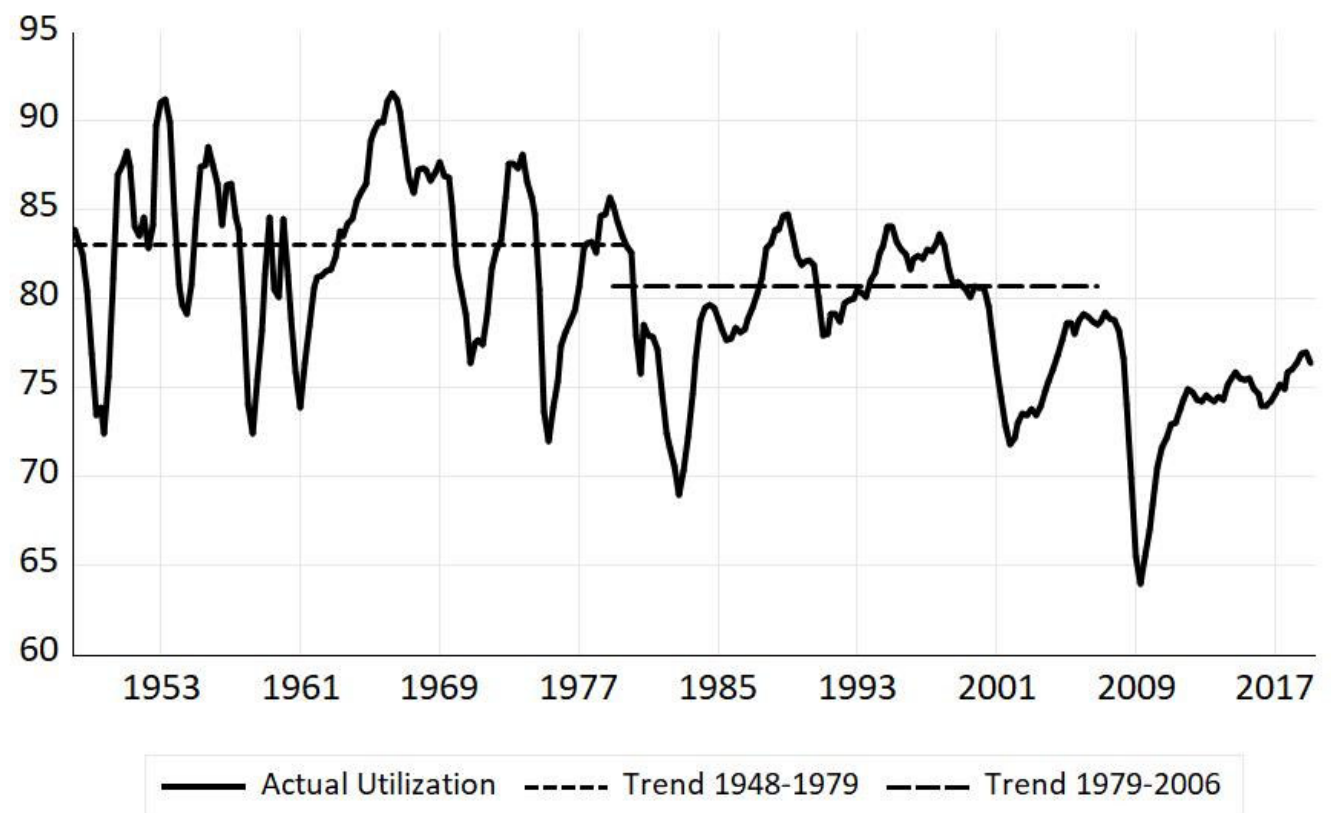

Source: Federal Reserve, reproduced from Nikiforos (2021)

Alternatively, and because of the decline in the FRB measure over the last twenty years, a concession has been made that it is likely that there is a small normal range of utilization. Demand can only play a role within this range.

I have explained elsewhere that if one looks at the way the FRB measure of utilization is constructed alongside the related documentation and literature, it is hard not to conclude that this measure tends to be stable by construction and therefore should not be used to answer the question of normal utilization's endogeneity (or lack thereof) in the long run (Nikiforos 2016: sec. 4.2; 2021: sect. 2). The methodology section of the FRB's webpage on "Capacity and Capacity Utilization Methodology" explains from the very beginning that the capacity indexes used for the construction of the measure of utilization capture a sustainable maximum output (Federal Reserve 2020). The sustainable maximum output is an economic definition of capacity, which is ambiguous. It is likely that demand plays a role in its determination, as a long period of high demand might make a higher level of production sustainable. 
Related to that, the FRB utilization rate is constructed with information from the Survey of Plant Capacity (SPC) conducted by the US Census Bureau. In this survey, plant managers are asked to report the "full production capability of their plant- the maximum level of production that this establishment could reasonably expect to attain under normal and realistic operating conditions fully utilizing the machinery and equipment in place." Again, "normal and realistic conditions" is an ambiguous phrase. If for a long period of time a plant operates for one shift, then this one shift reflects its normal and realistic conditions. If a persistent increase in demand — or some other reason—leads to the plant operating for two shifts over a long period of time, then these two shifts become the new normal and realistic conditions.

In other words, because of the ambiguous definitions of "sustainable maximum output" and "full production capability," the definition of capacity - the denominator of the rate of capacity utilization — becomes ambiguous as well. Factors such as demand that affects output in the numerator can also affect the denominator, leaving the overall rate relatively stable. ${ }^{2}$

There is, however, a more fundamental logical reason why a relatively stable measure of utilization cannot be used to evaluate whether utilization is endogenous to demand in the long run. The theory of utilization highlights several factors — besides demand - that affect utilization (see Nikiforos [2013] and references therein). These factors are:

1. Capital intensity.

2. Relative prices of labor and capital.

3. The rhythmic variation of input prices, such as the shift differential (a wage premium paid to workers who work other than "normal" working hours).

4. Rhythmic variations in demand.

\footnotetext{
${ }^{2}$ In Nikiforos (2021: sect. 2) I explain that this ambiguity was confirmed to me in personal correspondence by Federal Reserve economists who are involved in creating index and that there is also a significant body of literature that points toward that direction.
} 


\section{Economies of scale.}

6. The degree of monopoly in the market.

Ceteris paribus, higher capital intensity, a higher relative price of capital, lower rhythmic variations of input prices, a lower level of economies of scale, and a lower degree of monopoly lead to higher utilization.

A measure of utilization that remains stable over the long run (or over long stretches of time) would mean that all these different factors move in such a way that utilization remains stable. However, it is unclear why that would happen, unless by a fluke. And, if one is ready to accept such a fluke, then demand could be one of these factors as well.

An important implication of this logical argument is that nonstationary equilibrium should be expected irrespective of whether one believes that it is endogenous to demand. Thus, the interesting research question is not whether utilization is stationary or not, but whether demand contributes to the nonstationarity. I will turn to this in the following sections.

An alternative measure of utilization that does not suffer from these ambiguities is the aforementioned AWW. Using this measure the definition of capacity is the maximum time a plant can run during a week (168 hours), which provides an unambiguous denominator for measuring utilization. On the other hand, a major drawback of the AWW is that it cannot capture changes in utilization through changes in its speed of operation. In some industries this is an important margin of adjustment.

This disadvantage aside, the AWW is a better measure of long-run utilization. Several estimates of the AWW (Foss 1984, 1995; Shapiro 1986; Taubman and Gottschalk 1971; Orr 1989; Gorodnichenko and Shapiro 2011) present a very different picture compared to the 
FRB rate of utilization. ${ }^{3}$ For example, Foss (1984) found that between 1929 and 1976 there was an increase in the AWW close to 25 percent.

\section{THE NATIONAL EMERGENCY UTILIZATION RATE (NEUR)}

A measure of utilization that largely avoids ambiguities and is therefore useful for evaluating utilization's long-run trajectory is the US Census Bureau's national emergency utilization rate (NEUR).

Like the FRB measure, the NEUR is based on the Census's SPC. Aside from asking plant managers to report their plant's full production capability, the survey also asks them to estimate their national emergency production.

More precisely, for estimating their national emergency production, the SPC (US Census Bureau 2018, 5) asks managers to :

1. Assume full use of all machinery and equipment in place (including machinery and equipment that would require extensive reconditioning before they could be made operable).

2. Assume minimal downtime and multishift operations.

3. Assume plant production as close to 168 hours per week as possible, including extra shifts (e.g., operating 7 days per week, 24 hours per day, less minimal downtime).

4. Assume overtime pay, labor, materials, utilities, etc., are fully available to you and your suppliers.

5. Assume you can sell all your output.

6. Assume your product mix can change.

\footnotetext{
${ }^{3}$ A detailed discussion of these series is provided in Nikiforos (2016, 2019). In Nikiforos (2016: sect. 7) there is a simple econometric exercise that shows short-run variations of utilization affect the Taubman and Gottschalk (1971) and Orr (1989) measures of the AWW.
} 
7. Assume increased use of productive facilities outside the plant for services (such as contracting out subassembly work) in excess of the proportion that would be normal during the quarter.

This national emergency production is close to an engineering measure of capacity and therefore avoids the ambiguities of estimating full production capability.

The NEUR is calculated as the ratio between actual and national emergency production. An advantage of this measure compared to the AWW is that NEUR also captures variations in the speed of the production process and not only in the time plants are being used. The SPC's third point makes clear that 168 hours per week is the least common denominator of the two measures.

\section{Figure 2: The US Census National Emergency Utilization Rate}

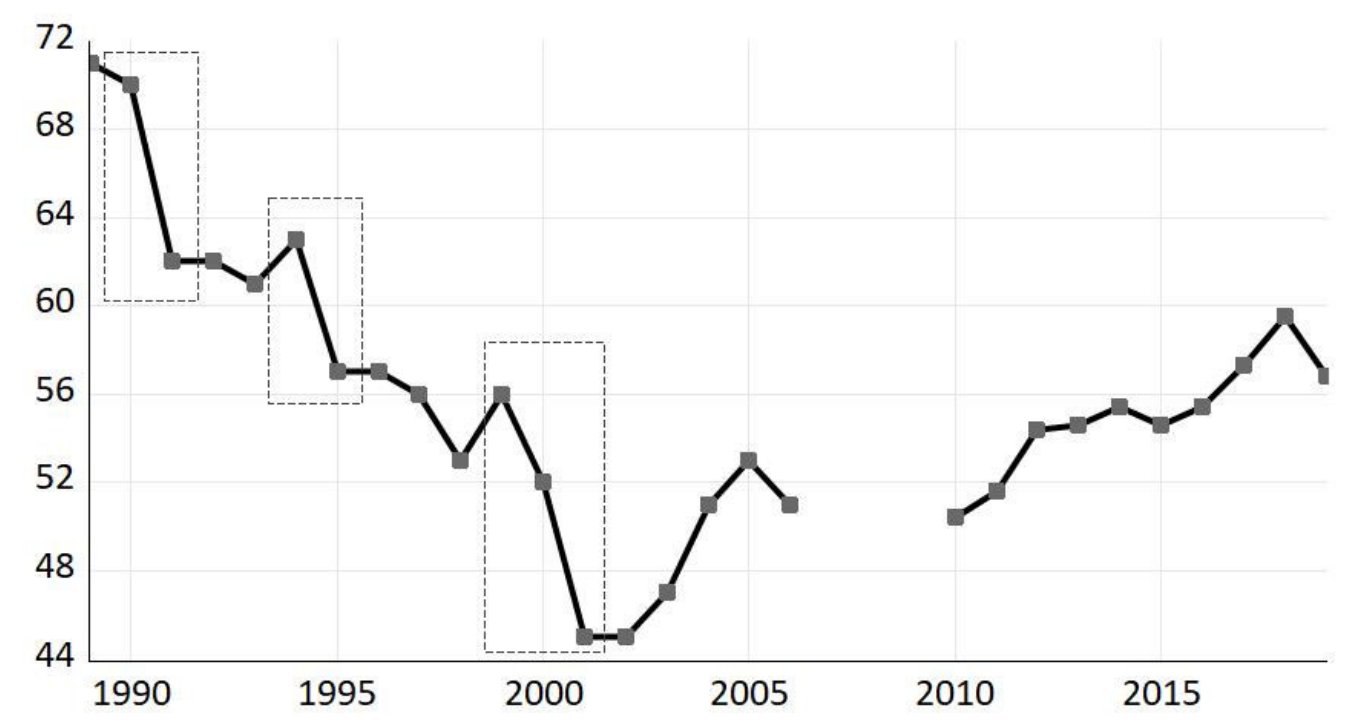

Source: US Census Bureau

The Census reports this estimate of utilization for the period 1989-2019, with the break in the years of the crisis (2007-9). Both 1989 and 2019 are peak-cycle years and are therefore suitable for comparison. The related series are presented in figure 2 . NEUR is obviously 
lower that than the FRB rate because, by definition, national emergency production is higher than full production capability.

Its trajectory is very different compared to the FRB measure. The two series are compared in figure 3, which presents their change from their 1989 level. As we can see:

- In 1999, one decade into the sample, the NEUR was 15 percentage points below its 1989 level. At the same time, the FRB rate was only 0.8 percentage points lower.

- In 2001, after the dot-com crisis, the NEUR was 26 points below, while the FRB rate was only 10 points.

- In 2006, at the peak of the business cycle and two cycles after 1989, the NEUR was 20 points below its 1989 level, while the FRB rate was only 2.8 points below.

- Finally, in 2019, after three cycles (and the two longest recoveries in US history) the NEUR had lost 14.2 points, while the FRB rate only lost 6.6 points. 


\section{Figure 3: Emergency and FRB Rates (difference from their 1989 level)}

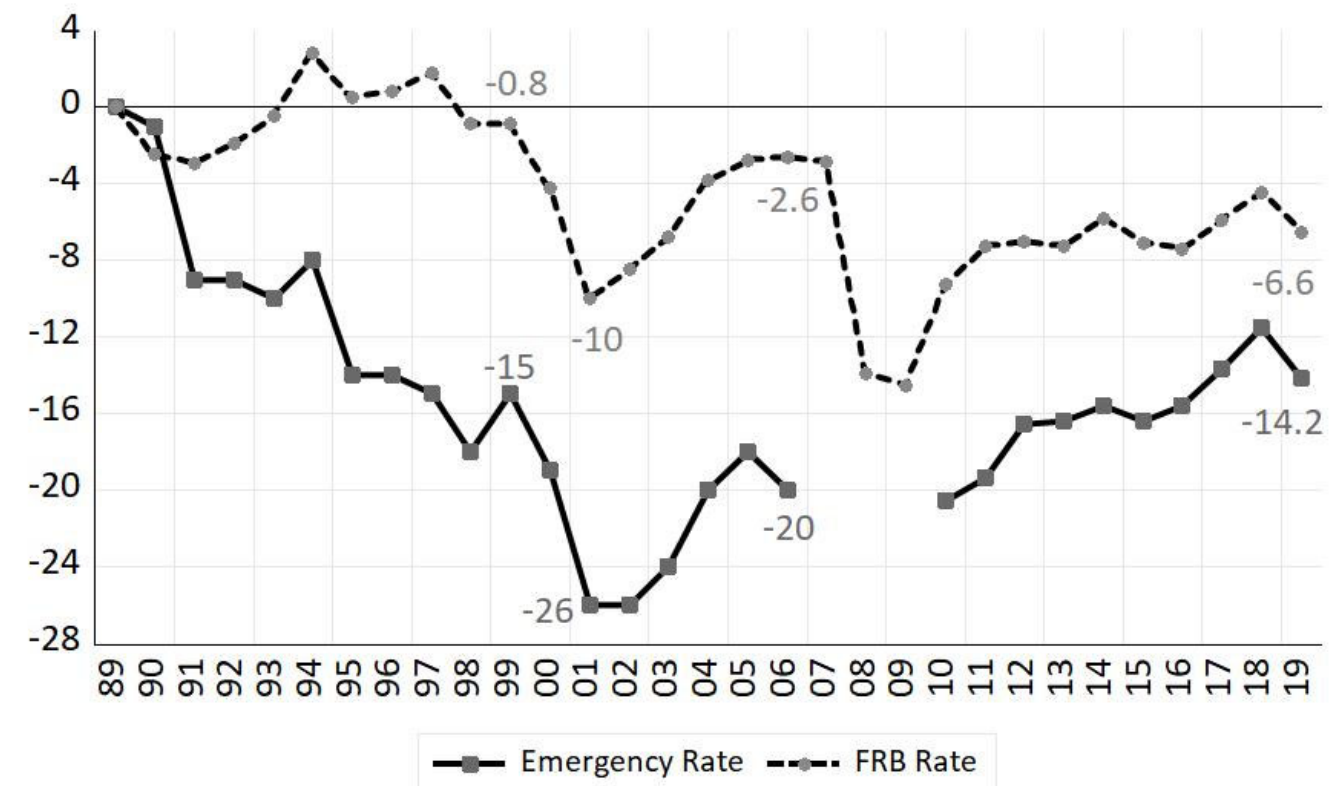

Sources: Federal Reserve, US Census Bureau, and author's calculations

It is worth mentioning that since national emergency production is, by definition, higher than full production capability (and therefore the denominator in the NEUR is higher than the FRB rate) a certain change in actual output (in the numerator) leads to a bigger change in the FRB rate compared to the NEUR. Therefore, if the ratio of full production capability to national emergency production remained constant, changes in actual output would produce changes in the two measure of utilization that would be the exact opposite of what we see in figure 3 . This confirms the conclusion that full production capability is conventional and adjusts toward actual production, making the FRB rate inappropriate for evaluating the behavior of the "normal" rate of utilization. 


\section{WHY HAS NEUR DECREASED?}

The NEUR has clearly decreased significantly over the period 1989-2019. As was explained above this does not necessarily mean that demand plays a role. The decline might be due to other factors. In this section I go through the various factors that have been identified in the related theory as important determinants of utilization (already mentioned in section 2) and examine if their trajectory can explain the NEUR's decline.

To give a preview of the results, I find that over the last thirty years most of these factors moved in a direction that would justify an increase in utilization. The decrease in the NEUR can only be explained by aggregate demand and maybe to a lesser extent by the increase in industrial concentration.

\subsection{Capital Intensity and the Relative Price of Labor and Capital}

The degree of capital intensity and the price of capital (relative to labor) can be approximated with the labor share of income. Higher capital intensity and a higher relative price of capital imply: i) a lower wage share, and ii) a higher normal level of utilization.

As it is well-known, and as presented in figure 4 (panel a), the labor share has dramatically decreased over the several last decades. ${ }^{4}$ All other things equal, this increase should have led to an increase in capacity utilization.

\subsection{Rhythmic Variations in Demand}

One reason why firms maintain excess capacity is to be able to cover fluctuations in demand so that they do not lose market share during an upswing. Hence higher variability of demand leads - all other things equal — to a lower normal rate of utilization.

\footnotetext{
${ }^{4}$ This decrease is even more pronounced if we control for the wages of the top 1 percent of the income distribution.
} 
Panel a in figure 4, presents a five-year backwards moving variance for real output and industrial production. What we can see is that the period of the decrease in the NEUR coincides with the decrease in the variability of demand. It is this decrease that Ben Bernanke (2004) called "The Great Moderation." Hence in this case the decrease in output variability should also have led to an increase in normal utilization. 


\section{Figure 4: Determinants of Utilization}
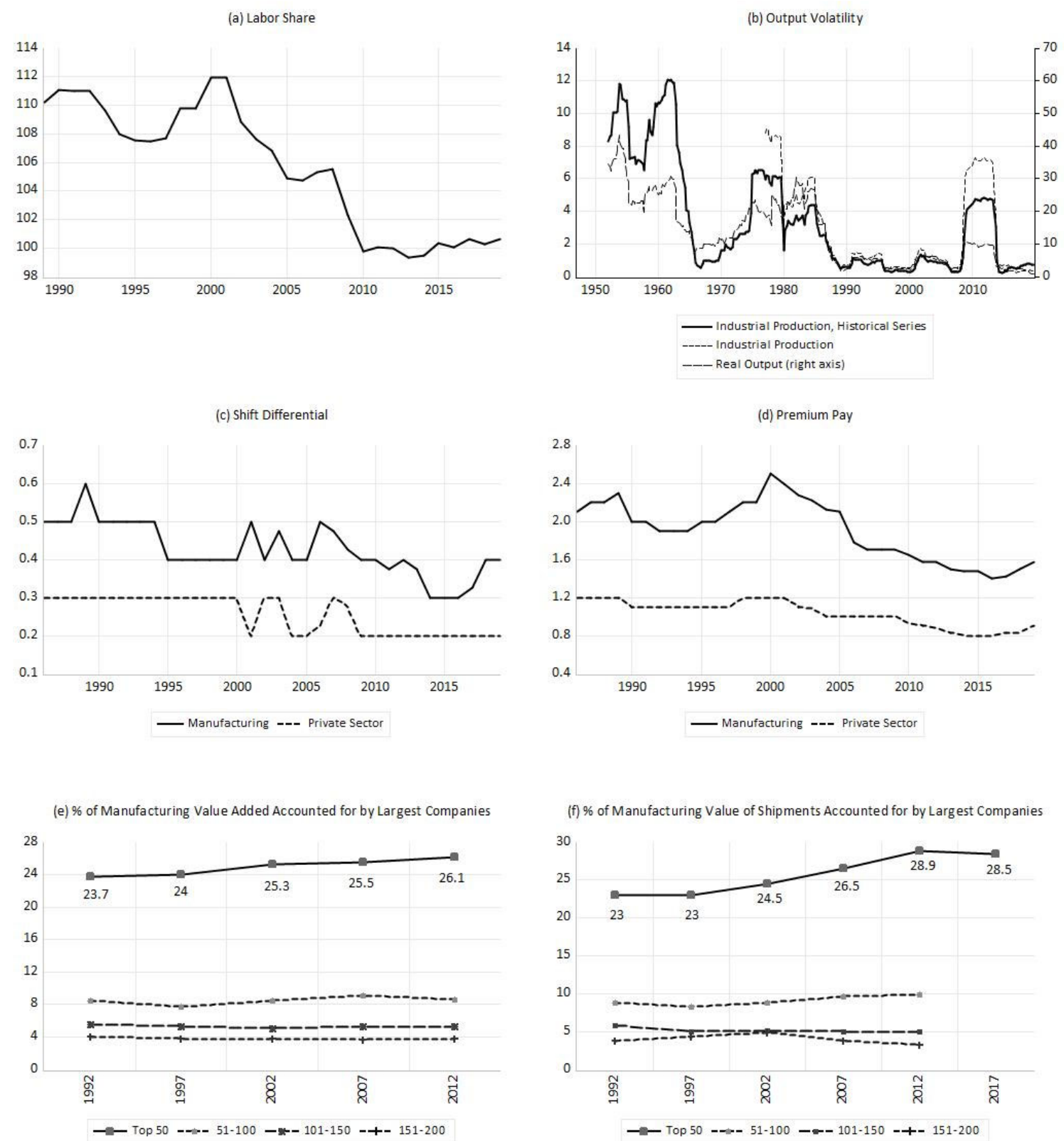

Sources: panels (a), (c), and (d): Bureau of Labor Statistics; panel (b): Federal Reserve, Bureau of Economic Analysis; panels (e) and (f) US Census Bureau

Notes: Panel (a): index 2012=100; panel (b): volatility as five-year backwards moving variance; panels (c) and (d): shift differential and premium pay as percentage of total compensation; panel (d): premium pay includes premium pay for work in addition to the regular work schedule (such as overtime, weekends, and holidays) 


\subsection{The Utilization (Shift) Differential}

Working late hours or night shifts is usually compensated with a higher wage. The difference between the wage for work during normal hours and the wage for late-hour or night-shift work is called the utilization (or shift) differential. All other things equal, an increase in the shift differential leads to a decrease in utilization as it makes extra shifts more expensive.

Figure 4 (panel c) presents the shift differential for the private sector and manufacturing during the period 1986-2019, expressed as a percentage of total compensation. We can make two observations. One, the shift differential was quite small to begin with. Two, if anything, it has decreased over the period under examination.

To complete the picture, figure 4 (panel d) presents the premium pay over the same period, again expressed as a percentage of total compensation. Premium pay includes pay for work in addition to the regular work schedule (such as overtime, weekends, and holidays). These payments might be part of what some companies consider a utilization differential. We can see that premium pay has also decreased.

The decreases in the shift differential and premium pay should have increased utilization.

\subsection{The Degree of Monopoly in the Market}

Figures 4 (panels e and f) present two measures of industrial concentration for the manufacturing sector: the percentage of value-added and total shipments by each sector's biggest companies (the top 50, the next 50, i.e. 51-100, etc.). They show that over the last three decades there has been in increase in industrial concentration in manufacturing and that this increase is concentrated among companies at the very top. Second, the magnitude of the increase depends crucially on the measure used. If we focus on value-added, the increase in the share of the top 50 companies over the period 1992-2012 is 2.4 percent, while when it comes to the value of shipments this increase is 5.5 percent 
According to the theory of utilization, an increase in industrial concentration can lead to a decrease in utilization, as oligopolistic or monopolistic companies use lower utilization as an entry deterrent. Hence, industrial concentration is the only among of the various factorsother than demand - that affect utilization that has moved in a direction compatible with a decrease in normal utilization. At the same time, it is hard to reconcile the magnitude of the decrease in utilization (close to 16 percent until 2017) with the magnitude of the increase in industrial concentration, and the fact that this has affected only very few firms at the top.

\subsection{Other Factors}

Justin Pierce and Emily Wisniewski (2018), who work for the Federal Reserve department that publishes the measure of utilization, discuss some other reasons that might explain the decline in the FRB rate of utilization. Their note rules out that this decline is the result of shifts in industry weighting and differences between continuing and entering/exiting establishments.

The latter is important also in relation to the role that industrial concentration might have played. As it was mentioned above, monopolies lower utilization as an entry deterrent. Since the entering and exiting behavior of firms cannot explain a decrease in the rate of utilization, it is unlikely that the increase in industrial concentration has played a significant role in the NEUR's decrease.

\subsection{What About Demand?}

So far, the examination of the various factors for the determination of normal utilization showed that they all — with the exception of industrial concentration — moved in a direction that should have led to an increase in utilization. It is thus hard to reconcile the observed steep decrease in NEUR with the trajectory of these structural factors.

There are good reasons to believe that deficient aggregate demand is the main reason behind this decrease in the NEUR. In figure 1, I also marked in dotted squares the three main periods of a decreasing NEUR: 1991, 1995, and 2000-1. We can see that the two main downward 
moves in the NEUR took place during the recessions of the early 1990s and early 2000s. In between, the NEUR also decreased significantly in 1995, which was also a year of economic slowdown, although it was not officially recorded as a recession. ${ }^{5}$ Thus, figure 1 provides support for a demand-determined, path-dependent behavior of the normal rate of utilization.

The main reason behind the NEUR's nonrecovery is weak aggregate demand. Figure 5 presents the US economy's average growth rate for every decade since the 1930s. As we can see, the 2000s and 2010s are the decades with — by far - the lowest growth rates in the postwar period. The growth rate in the 2000s is even lower than that of the 1930s; the growth rate of 2010s is more or less the same as the decade of the Great Depression.

\section{Figure 5: Average Growth Rate by Decade}

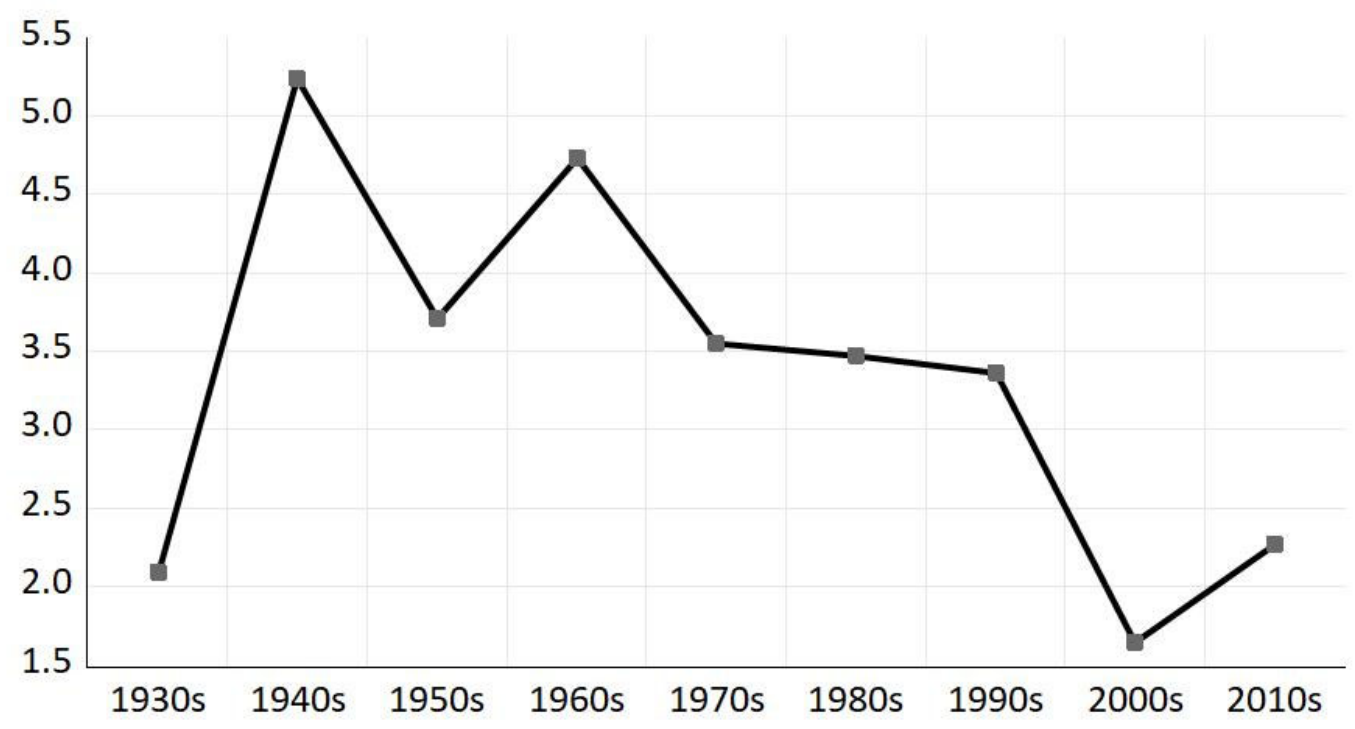

Source: BEA and author's calculation

\footnotetext{
${ }^{5}$ The ideas of the Great Moderation originated in the events of 1995 (i.e., that appropriate monetary policy can mitigate the cycle) and Alan Greenspan's outsized influence (at least until 2007). The Federal Reserve had started increasing interest rates in early 1994, and by the spring of 1995 there were fears of an imminent downturn. The Fed responded by reversing monetary tightening and decreasing effective rates. Greenspan $(2008,156)$, in his Age of Turbulence, writes that "...the soft landing of 1995 was one of the Fed's proudest accomplishments during my tenure." The events of 1995 resurfaced in the summer of 2019, when the US economy started slowing down.
} 
Another way to see this is presented in figure 6, which shows the trajectories of US real GDP and manufacturing output (panel a and panel b, respectively) for all postwar recoveries. It is clear that the latest three have been the slowest recoveries among all postwar recoveries, with the last one (2009Q2-2019Q4) the slowest of them all. At the same time, the recoveries of the 2010s and the 1990s were the longest in the US history; hence the reduction of variability and the arguments of the Great Moderation.

Figure 6: Real GDP and Industrial Production in Postwar US Recoveries (trough=100)

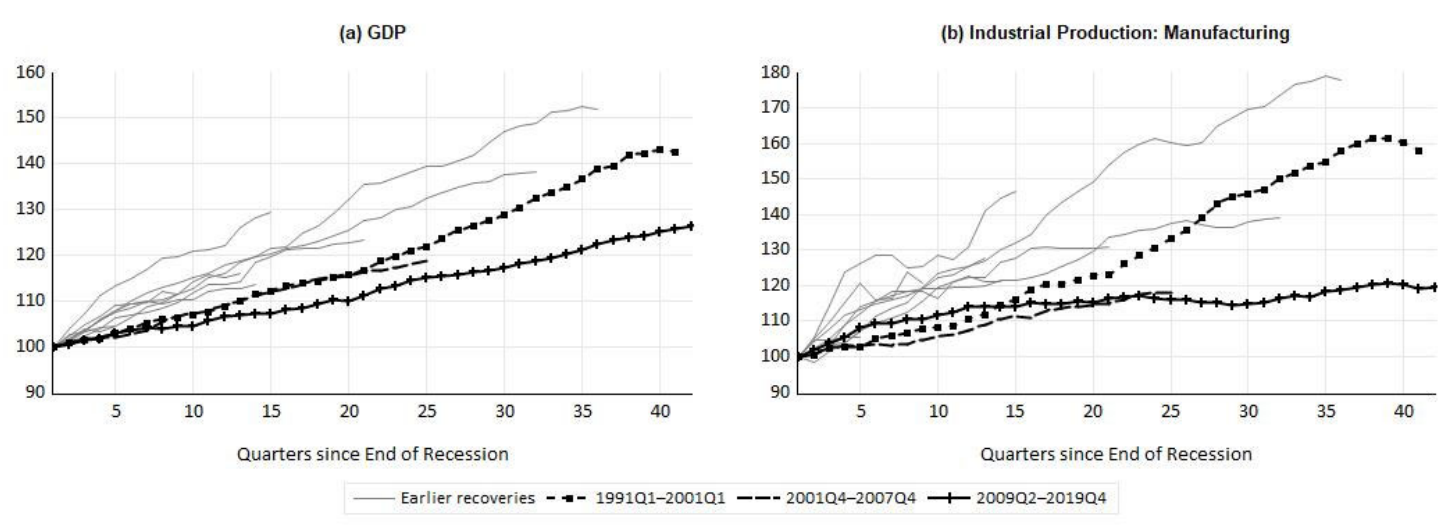

Source: BEA, author's calculations

This "secular stagnation" of the last several decades has been widely discussed in the literature. To the extent that it is due to deficient aggregate demand-and there are good reasons to believe it is (Nikiforos 2020a) — then this stagnation has naturally led to the decrease of utilization.

Finally, this decrease in NEUR is compatible with the trajectory of investment over the same period. Figure 7 presents an index of real investment in structures and industrial equipment in manufacturing, used here as a proxy for investment in fixed capital in manufacturing. The figure shows that these categories of investment have stagnated since 1980. In the twenty years before (1960-80) these categories of real investment more than quadrupled. In the fifty years that followed, the increase barely approached 50 percent. In the twenty-five years 
between the mid-1990s and 2019 this kind of real investment increased by roughly 25 percent. $^{6}$

Figure 7: Index of Real Investment in Structures and Industrial Equipment in Manufacturing (1997q1=100)

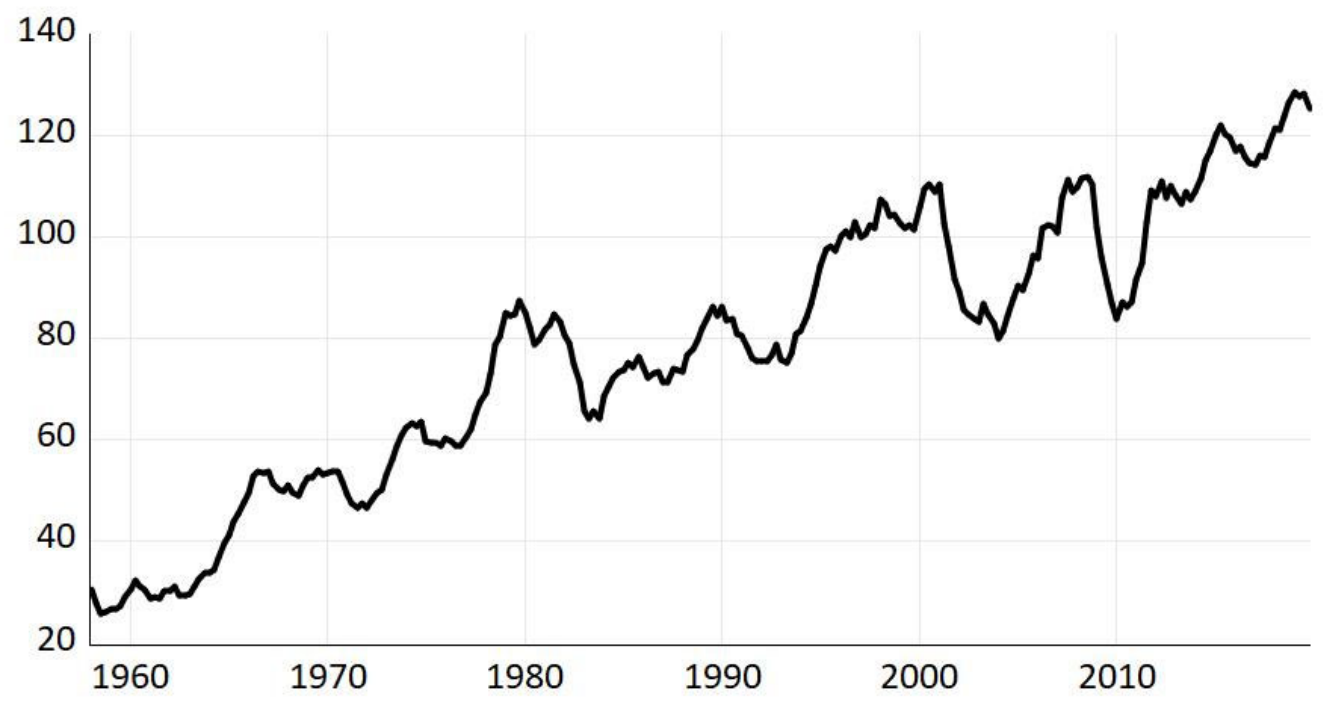

Source: BEA and author's calculations

\section{CONCLUSION}

The argument in favor of an exogenous rate of utilization - or a normal utilization that fluctuates within a small range - is usually empirically justified with the use of the FRB rate of utilization that has been relatively stable (at least until recently). However, if one looks carefully at the method of construction it becomes obvious that the FRB rate tends to be

\footnotetext{
${ }^{6}$ Duménil and Lévy (2012) discuss the decrease in the FRB rate of utilization and they dismiss the Keynesian explanation of deficiency of aggregate demand on the basis that the last half of the 1990s saw a very strong increase in investment in manufacturing. Figure 7 shows that this is not the case. It is also worth mentioning that an increase in investment over a short period of time does not necessarily mean that utilization is high. In fact, assuming that investment increases over a period due to reasons other than utilization (positive expectations, animal spirits, etc.) would lead to a decrease in utilization over the short run.
} 
stationary by construction. More importantly a rate of utilization that is stationary over the long run is not compatible with the theory of utilization.

Thus, we should move beyond discussing if utilization is stationary or not. It is not, and it should not be (even if demand does not matter). More interesting tasks would include: i) finding measures of utilization that can capture long-run variations of normal utilization, and ii) examining how the various determinants of utilization, as specified in the related theory, have affected them.

The present paper is a contribution toward that direction. It discussed the NEUR, as published by the US Census Bureau. Over the period 1989-2019—after three cycles and the two longest recoveries in US history-NEUR decreased by 14.2 percent. Different explanations - based on the theory of capacity utilization-were considered.

It was shown that most of the factors that affect utilization have moved in the opposite direction, i.e., toward a direction that would have led — all other things equal— to an increase in the rate of utilization. The factor that seems to have contributed most to the decrease in utilization was low aggregate demand, while the increase in industry concentration might have played a small role.

This paper also provides some hints for interesting follow-up research. In particular, a sectoral decomposition and/or an analysis based on micro data would shed more light on the factors that have led to the decrease in utilization. 


\section{REFERENCES}

Bernanke, B. 2004. "The Great Moderation: Remarks by Governor Ben S. Bernanke at the Meetings of the Eastern Economic Association." February 20, Washington, DC.

Duménil, G., and D. Lévy. 2012. "Being Post-Keynesian in the Medium Term and Classical Marxian in the Long Term?" Available at:

http://www.cepremap.fr/membres/dlevy/dle2012o.pdf

Federal Reserve. 2020. "Industrial Production and Capacity Utilization.” Available at: https://www.federalreserve.gov/releases/g17/Meth/MethCap.htm.

Foley, D. K., T. Michl, and D. Tavani. 2019. Growth and Distribution. Cambridge, MA: Harvard University Press.

Foley, D. K., and T. Michl. 1999. Growth and Distribution. Cambridge, MA: Harvard University Press.

Foss, M. F. 1984. Changing Utilization of Fixed Capital: An Element in Long-Term Growth. Washington, DC: American Enterprise Institute for Public Policy Research.

. 1995. "Operating Hours of the US Manufacturing Plants, 1976-1988, and Their Significance for Productivity Change.” In D. Anxo, G. Bosch, G. Cette, T. Sterner, and D. Taddei (eds.) Work Patterns and Capital Utilisation: An International Comparative Study. London: Kluwer Academic Publishers.

Gorodnichenko, Y., and M. D. Shapiro. 2011. "Using the Survey of Plant Capacity to Measure Capital Utilization.” Center for Economic Studies Working Paper No. 1119: Washington, DC: Center for Economic Studies, US Census Bureau.

Greenspan, A. 2008. The Age of Turbulence: Adventures in a New World. London: Penguin UK.

Michl, T. 1987. “An Anatomy of the Reagan Recovery.” In R. Cherry, C. D’Onofrio, C. Kurdas, T. Michl, F. Moseley, and M. Naples (eds.), The Imperiled Economy. New York: The Union for Radical Political Economics.

- 2009. Capitalists, Workers, and Fiscal Policy: A Classical Model of Growth and Distribution. Cambridge, MA: Harvard University Press.

_ 2015. "A Model of Fiscal and Monetary Policy." In L. Taylor, A. Rezai, and T. Michl (eds.), Social Fairness and Economics: Economic Essays in the Spirit of Duncan Foley. London and New York: Routledge. 
Michl, T., and D. K. Foley. 2004. "Social Security in a Classical Growth Model." Cambridge Journal of Economics 28(1): 1-20.

Nikiforos, M. 2013. "The (Normal) Rate of Capacity Utilization at the Firm Level." Metroeconomica 64(3): 513-38.

- 2016. "On the 'Utilisation Controversy': A Theoretical and Empirical Discussion of the Kaleckian Model of Growth and Distribution." Cambridge Journal of Economics 40 (2): 437-67.

— 2019. "On the 'Utilization Controversy': A Rejoinder and Some Comments." Cambridge Journal of Economics 4(3): 709-22.

_ 2020a. "Demand, Distribution, Productivity, Structural Change, and (Secular?) Stagnation." Levy Economics Institute Working Paper No. 945. Annandale-onHudson, NY: Levy Economics Institute of Bard College.

—. 2020b. "Notes on the Accumulation and Utilization of Capital: Some Theoretical Issues." Levy Economics Institute Working Paper No. 952. Annandale-on-Hudson, NY: Levy Economics Institute of Bard College.

— 2021. "Notes on the Accumulation and Utilization of Capital: Some Empirical Issues." Metroeconomica (online first). doi: https://doi.org/10.1111/meca.12339

Orr, J. A. 1989. "The Average Workweek of Capital in Manufacturing, 1952-1984." Journal of the American Statistical Association 84(405): 88-94.

Pierce, J. R, and E. Wisniewski. 2018. "Some Characteristics of the Decline in Manufacturing Capacity Utilization.” FED Notes, March 1.

Shapiro, M. D. 1986. "Capital Utilization and Capital Accumulation: Theory and Evidence." Journal of Applied Econometrics 1(3): 211-34.

Taubman, P., and P. Gottschalk. 1971. "The Average Workweek of Capital in Manufacturing." Journal of the American Statistical Association 66(335): 448-55.

United States Census Bureau. 2018. "Instructions for the quarterly survey of plant capacity utilization." Washington DC: United States Census Bureau. 